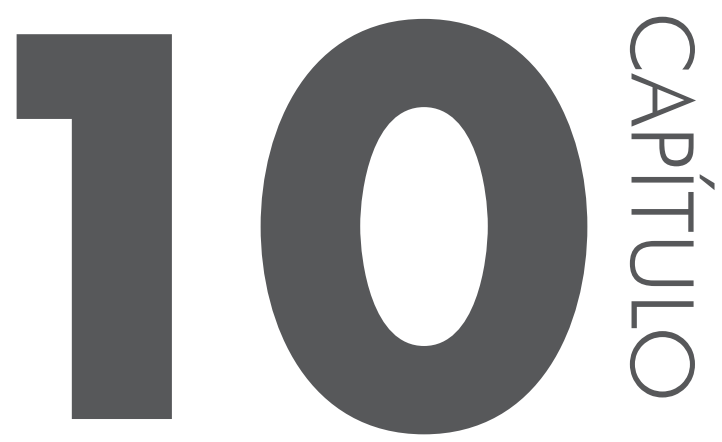

\title{
PROPOSTA DE UM SISTEMA DE GESTÃO PARA FISCALIZAC̣ÃO AMBIENTAL
}

Laudelino Joaquim

Luciana Bolan Frigo

Eliane Pozzebon

\section{INTRODUC̣ÃO}

As organizações responsáveis em preservar o meio ambiente, de modo equilibrado e que forneça qualidade de vida para as pessoas, precisam buscar técnicas para reduzir a degradação e recuperar o dano já ocasionado. Para que isso torne-se possível, são necessárias estratégias que permitam a evolução econômica e financeira sem o comprometimento das fontes de recursos naturais.

Apesar do grande investimento em pesquisas para o desenvolvimento de novas técnicas na agricultura visando ao aumento da produtividade por hectares, muitos agricultores também buscam ampliar sua área de plantio, objetivando a 
elevação de sua renda e, em muitos casos, sem que haja qualquer preocupação com o dano ambiental gerado.

Considera-se que na contra mão do mau uso destas técnicas e tecnologias estão os órgãos ambientais de fiscalização. Em Santa Catarina, as duas principais instituições responsáveis pela fiscalização ambiental são a Fundação de Amparo à Tecnologia e ao Meio Ambiente (Fatma) e a Polícia Militar Ambiental (PMA). O principal cenário deste trabalho é a cidade de Maracajá e região, onde não há sistema que registre ou controle a área utilizada no avanço agrícola nem a mensuração dos danos ocasionados. Mesmo quando esses danos são diagnosticados, tais órgãos ambientais não possuem ferramentas computacionais adequadas que os auxiliem no processo de monitoramento das atividades realizadas, como a recuperação dos danos ambientais.

A maioria dos documentos é preenchida manualmente, aumentando a possibilidade de erros e de inconsistência nos dados, o que dificulta o acompanhamento das infrações. Os principais setores produtivos na região de Maracajá, com importante impacto ambiental, são a rizicultura, o agronegócio (frigoríficos de frangos e suínos) e a extração de minerais (carvão, argila e areia), e estes setores estão crescendo e, por vezes, adotando estratégias ilegais que lhes proporcionem vantagens em relação aos órgãos ambientais de fiscalização e controle. A falta de um sistema de gestão para registro, organização e controle das atividades rotineiras da PMA, que forneça informações precisas das áreas que estão sendo mais afetadas, a frequência e expansão do dano, prejudica o desempenho da Polícia Militar Ambiental e facilita a degradação do meio ambiente.

O objetivo deste trabalho é propor um sistema computacional de gestão ambiental, que possa ser aplicado pela Polícia Militar Ambiental em Santa Catarina.

\section{METODOLOGIA}

Foi realizada uma pesquisa junto aos órgãos ambientais de todo o Brasil que, de alguma forma, possam auxiliar no diagnóstico e contribuir para um sistema de gestão ambiental mais eficaz. Para tanto, serão contactados aos seguintes segmentos de fiscalização:

a) unidades de Polícia Militar Ambiental, instaladas na Região Sul e em algumas de outras regiões do país;

b) unidades da Polícia Militar Ambiental de Santa Catarina, instaladas em 18 cidades do estado e que tem como missão atender aos 295 municípios catarinenses;

c) fundações, secretarias e departamentos de meio ambiente, instalados nos 27 municípios que compõem a Associação dos Municípios do Extremo Sul Catarinense (Amesc) e Associação dos Municípios da Região Carbonífera (Amrec). 


\section{FUNDAMENTAÇÃO TEÓRICA}

Há acerca de 50 anos, grande parcela da população não tinha nenhuma preocupação com a qualidade do meio ambiente, pois entendia que os recursos naturais eram infinitos e que não haveria motivo para preservar ou fazer uso consciente desses recursos. Ao longo dos anos, o homem começou a perceber que dependia, sim, da qualidade do meio ambiente para que sua vida fosse também mantida em boas condições.

Em 1972 aconteceu a Conferência de Estocolmo. Desde então, o Brasil e outros países nunca mais foram os mesmos em relação à preservação ambiental, apesar de, nesta conferência, os países ricos e pobres não terem conseguido entrar em acordo. Passado algum tempo desde o Protocolo de Quioto, foi realizado um acordo para controle na emissão de poluentes e que cada nação deveria realizar ações e cooperar para que o meio ambiente fosse respeitado (CURI, 2012).

$\mathrm{Na}$ década de 1990, a gestão ambiental virou assunto para a ISO. Foi nesta época que nasceu a família ISO 14000, com o objetivo de nortear o ciclo de vida dos produtos, as auditorias e o Sistema de Gestão Ambiental (SGA), entre outras questões ligadas ao meio ambiente. As normas ISO 14000 não são leis; elas têm como objetivo principal ajudar as empresas a seguirem o rumo mais adequado para a sustentabilidade. A norma sobre SGA ficou conhecida no Brasil como NBR ISO 14001 - Sistema de Gestão Ambiental, sendo a única norma da série 14000 que oferece certificação (OMETTO; FILHO; PERES, 2013).

Faz parte da gestão ambiental dos órgãos licenciadores o Instituto Brasileiro do Meio Ambiente e dos Recursos Naturais Renováveis (Ibama) e a Fundação de Amparo à Tecnologia e ao Meio Ambiente (Fatma). Em Santa Catarina, há a cobrança de que o interessado na obtenção da licença realize um relatório técnico, chamado Estudo de Impacto Ambiental (EIA), que avalia as consequências para o ambiente decorrente de um determinado projeto. O EIA, ao contrário ao que o nome sugere, não se limita às questões do meio ambiente. No Art. $1^{\circ}$ da Resolução do Conselho Nacional do Meio Ambiente (Conama) de 1986, define como impacto ambiental qualquer alteração de natureza química, física e biológica do meio ambiente, bem como contra a saúde, segurança e bem-estar da população (PHILIPPI; ROMÉRO; BRUNA, 2010).

Na Polícia Militar Ambiental de Santa Catarina, existe um setor denominado Gestão de Educação Ambiental (GEA), que é responsável pelo suporte às unidades operacionais instaladas nos municípios, com o objetivo de organizarem e desenvolverem atividades educativas para serem levadas até as escolas conscientizando crianças e adolescentes. Os programas educativos atualmente existentes na PMA/SC são as Palestras em Sala de Aula, com uso de cartilhas de temas voltados ao meio ambiente, bem como o carro-chefe, o Projeto Protetor Ambiental 
(Proa), que contempla adolescentes de 12 a 14 anos com aulas no contraturno de seu ensino regular durante um semestre letivo.

\section{GESTÃO AMBIENTAL NA POLÍCIA MILITAR DE MARACAJÁ}

Na Polícia Militar Ambiental de Maracajá, as ocorrências recebidas via telefone são cadastradas em um base de dados elaborada por integrantes da própria unidade, com auxílio do software e aplicativo de banco de dados denominado Access, parte integrante do pacote Office, da Microsoft. As ocorrências são filtradas para, então, serem encaminhadas a uma guarnição para a fiscalização da referida solicitação.

As ocorrências também podem ser recebidas via ofício do Ministério Público Federal, do Ministério Público Estadual, das Delegacias de Polícia Civil, bem como por meio do Net Denúncia, um serviço disponibilizado no site da Polícia Militar de Santa Catarina, conforme mostra a Figura 10.1, no qual o cidadão pode registrar sua denúncia, de qualquer natureza, inclusive os crimes contra o meio ambiente, não havendo a necessidade de identificação do denunciante.

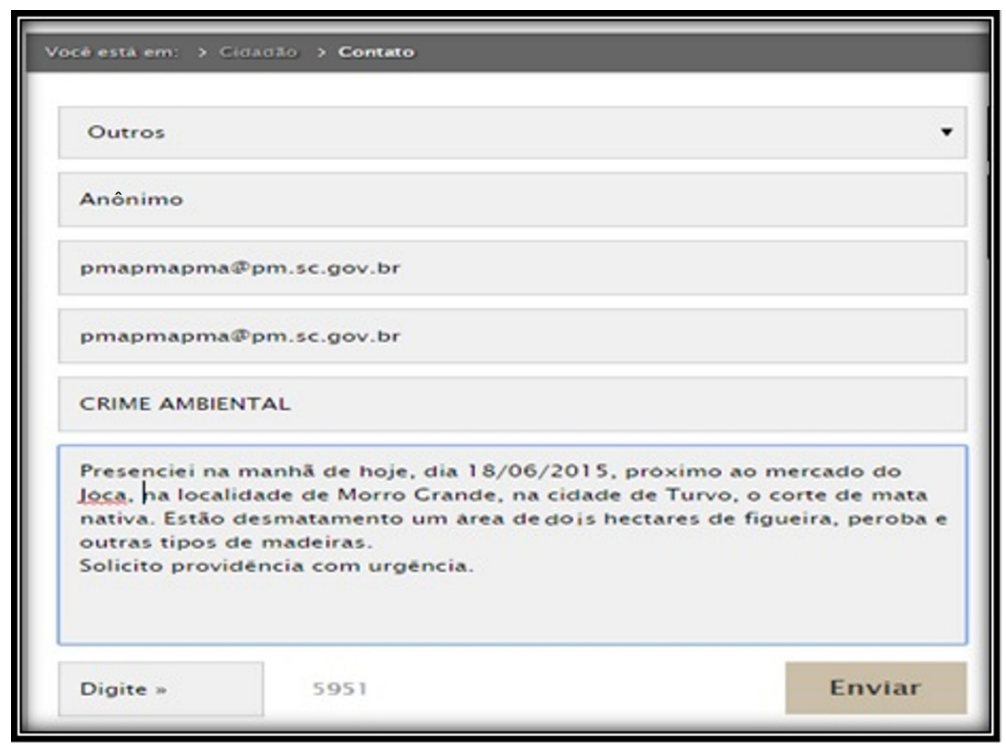

Figura 10.1 Formulário para Net Denúncia da PM/SC.

Após o cadastramento, a solicitação é repassada para uma guarnição de serviço que vai até o local do suposto cometimento da infração ambiental. Sendo confirmado o crime ambiental, a equipe de fiscalização confeccionará os documentos de acordo com cada situação. 
Os documentos costumeiramente preenchidos em um atendimento que flagram o delito ambiental são:

1) Auto de Infração Ambiental (AIA);

2) Termos de Embargos e Interdição (TEI);

3) Termos de Apreensão e Depósito (TAD);

4) Auto de Constatação (AC).

Ao término do atendimento das solicitações, o responsável pela guarnição de serviços confeccionará o relatório de serviço realizado, alimentará o sistema Access do cadastro das denúncias recebidas e fará a inserção dos documentos (AIA, TEI e TAD) em um sistema denominado GAIA, gerido pela Fatma para controle dos processos administrativos. Quando necessário, o AC será devidamente registrado em livros de protocolo da PMA, para posterior envio, via ofício, ao órgão solicitante.

Durante as pesquisas realizadas, não foi possível identificar nenhum estado brasileiro com um sistema computacional de gestão ambiental para o processo de ocorrências ambientais, sendo que cada unidade cria seu próprio meio de cadastro, gerenciamento e controle de suas ocorrências, e que, dessa forma, não há controle da situação atual dos danos ambientais no Brasil. Quando encontramos informativos com alguns dados de danos ambientais, estes dados nunca são reais e, sim, estimativos, pois não há sistema de controle devidamente instalado para gerir tais informações.

Dentre as situações identificadas, destaca-se a PMA de Foz do Iguaçu, no Estado do Paraná, que ainda registra a denúncia de um possível crime ambiental (comércio ilegal de lenha), conforme apresenta a Figura 10.2.

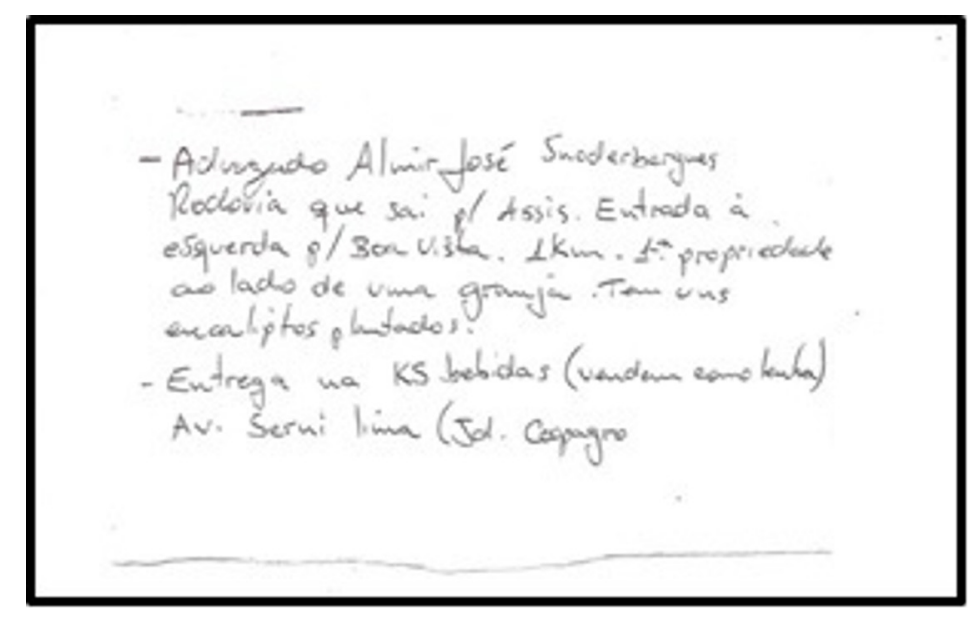

Figura 10.2 Registro de denúncia ambiental. 
No $2^{\circ}$ Pelotão de Polícia Militar Ambiental de Maracajá, unidade-base para realização das pesquisas, as denúncias chegam de várias formas (Net Denúncia, ofícios do Ministério Público Estadual e Federal, telefone ou diretamente na unidade), e as informações recebidas são gerenciadas da seguinte maneira:

1) Net Denúncia e ofícios dos Ministérios Públicos são organizados manualmente e entregues aos agentes para atendimento.

1) As denúncias recebidas via telefone ou diretamente na sede da Polícia Militar em Maracajá são cadastradas em uma base de dados. Neste momento, é realizado o cadastramento de informações, imprescindível ao atendimento da denúncia (telefone do solicitante, endereço de onde estaria ocorrendo o dano ambiental e descrição do fato observado pelo solicitante).

Com as informações cadastradas, o coordenador realiza uma filtragem e prioriza o atendimento, designando uma guarnição para realizar o atendimento. Após encerrar o atendimento, o policial realiza o fechamento da denúncia, inserindo no campo "Providências Tomadas" a descrição do que foi constatado no local do fato.

Ao realizar o atendimento das denúncias, e ao ser constatado que o fato configura crime ambiental, a guarnição precisa realizar o procedimento administrativo (multa) e criminal. Vários documentos precisam ser preenchidos para o cumprimento da legislação, que podem alterar o valor da multa a ser aplicada ao autuado pelo cometimento do crime ambiental.

É evidente e urgente a necessidade de um sistema de gestão ambiental voltados aos órgãos de fiscalização.

\section{SISTEMA PROPOSTO}

Propõe-se um sistema computacional de gestão ambiental voltado aos órgãos de fiscalização ambientais. Os requisitos do sistema foram levantados, usando técnicas de elicitação, como entrevista e análise de documentos (SOMMERVILLE, 2007), junto à Polícia Militar Ambiental de Maracajá, que almeja realizar uma gestão mais eficiente de suas atividades rotineiras.

O sistema deverá permitir o cadastramento de denúncias (Figura 10.3) e, em seguida, o coordenador realizará a filtragem dos fatos, priorizando os atendimentos mais urgentes (vazamento de produto tóxico, desmatamento, caça, extração de minerais etc.), para, então, determinar que uma guarnição desloque-se até o local do suposto dano ambiental e possa apurar os fatos. Neste estágio do processo, o sistema deveria possuir um módulo de sistema móvel (sistema compacto que rodaria com facilidade em um tablet utilizado pela guarnição), sendo que neste 
sistema móvel (Figura 10.4) estariam as mesmas funções do sistema principal para fechamento de ocorrência e geração do processo administrativo (AIA, TEI, TAD etc.).

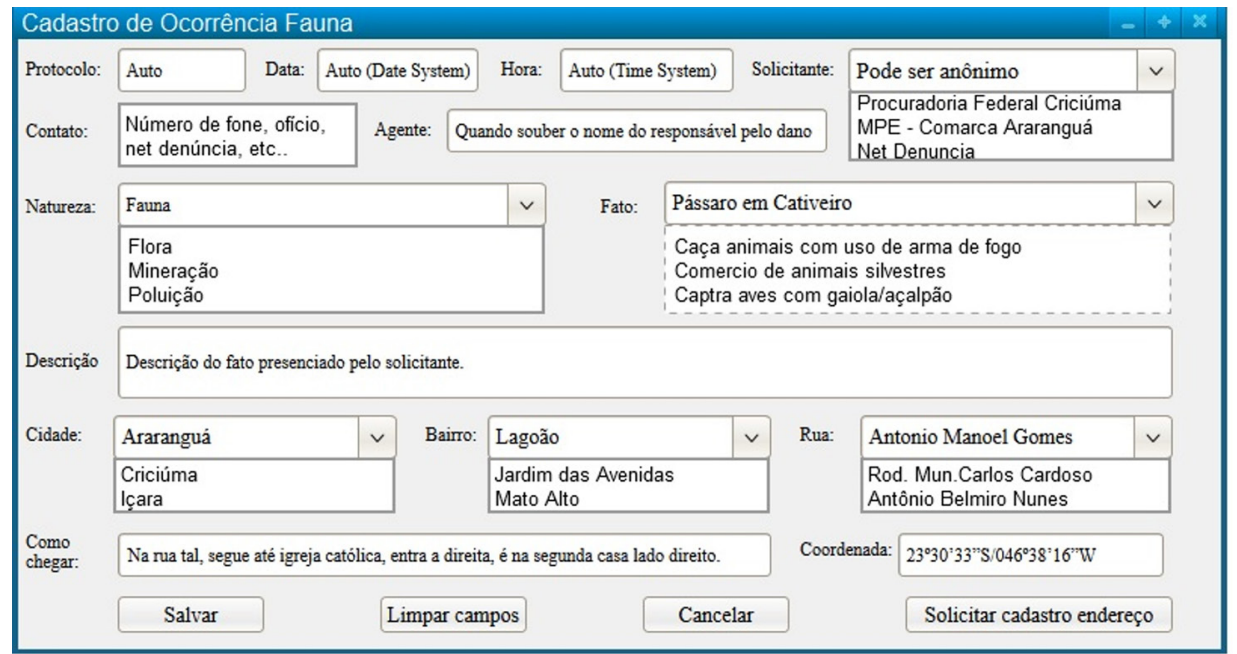

Figura 10.3 Cadastro de denúncia ambiental.

Serão inseridos os dados informados pelo solicitante, que gerarão a base de ocorrências a serem atendidas.

\begin{tabular}{|c|c|c|c|c|c|c|c|c|}
\hline \multicolumn{9}{|c|}{ Auto de Infração Ambiental - Criminal - Lei 9.605 (fauna) } \\
\hline Nome: & João da Silva & \multirow{2}{*}{$\mathrm{CPF} / \mathrm{CNPJ}$ : } & \multicolumn{2}{|c|}{$000.000 .000-00$} & $N^{\circ}$ AIA: & \multicolumn{3}{|l|}{ Auto } \\
\hline Data e Hora: & Vem de campo da tela "Encerrar Ocorrência" & & \multicolumn{2}{|c|}{$\square$ Termo de Embargo/Interdição } & \multicolumn{4}{|c|}{$\square$ Termo de Apreensão e Depósito } \\
\hline \multirow[t]{2}{*}{ Natureza: } & Fauna & $\checkmark$ & \multirow[t]{2}{*}{ Artigo: } & \multicolumn{5}{|c|}{29 - Matar, perseguir, caçar, espécimes fauna silvestre $\vee$} \\
\hline & \multicolumn{2}{|l|}{\begin{tabular}{|l|} 
Flora \\
Mineração \\
Poluição
\end{tabular}} & & \multicolumn{5}{|c|}{$\begin{array}{l}\text { Art. 30. Exportar peles/couros de anfibios e répteis. } \\
\text { Art. 32. Praticar maus-tratos animais } \\
\text { Art. 34. Pescar em periodo em que pesca seja proibida }\end{array}$} \\
\hline \multirow{3}{*}{$\begin{array}{l}\text { Descrição: } \\
\text { Parágrafo: }\end{array}$} & \multicolumn{8}{|c|}{$\begin{array}{l}\text { Art. 29. Matar, perseguir, caçar, apanhar, utilizar espécimes da fauna silvestre, nativos ou em rota migratória, sem a } \\
\text { devida permissão, licença ou autorização da autoridade competente, ou em desacordo com a obtida: }\end{array}$} \\
\hline & $\S 1^{\circ}$ Incorre nas mesmas penas: & $\checkmark$ & \multirow[t]{2}{*}{ Item: } & \multicolumn{3}{|c|}{ I - quem impede procriação da fauna, sem licença. } & & $\checkmark$ \\
\hline & \multicolumn{2}{|l|}{$\begin{array}{l}\S 2^{\circ} \text { No caso de guarda doméstica } \\
\S 3^{\circ} \text { São espécimes da fauna silvestre } \\
\S 4^{\circ} \mathrm{A} \text { pena é aumentada de metade }\end{array}$} & & \multicolumn{5}{|c|}{$\begin{array}{l}\text { II - quem modifica, danifica ou destrói ninho, abrigo; } \\
\text { III - quem vende, adquire, guarda, tem em cativeiro. }\end{array}$} \\
\hline & Salvar e avançar & Salvar e fechar & & Limpar campos & \multicolumn{4}{|c|}{ Cancelar } \\
\hline
\end{tabular}

Figura 10.4 Preenchimento de AIA.

Ao inserir as informações no sistema, será possível preencher todos os documentos sem a necessidade de retrabalho que ocorre com o preenchimento manuscrito. 
É importante ressaltar que tal sistema deveria ter seu funcionamento também no modo off-line, pois as atividades da PMA, em geral, são realizadas em áreas rurais, nas quais, muitas vezes, não existem conexões com redes de transmissão de dados, sendo que o agente fiscalizador faria todo procedimento em seu equipamento eletrônico como se estivesse na base da PMA e, ao chegar a locais com acesso às redes de comunicação, o sistema automaticamente faria a sincronização e passaria todas as informações aos servidores e o fato apurado estaria liberado ao acesso de todos que possuem privilégio para tal pesquisa.

Para realmente atender à expectativa gerencial da unidade de PMA de Maracajá, é necessário elaborar consultas, relatórios e representações gráficas que possibilitem o mapeamento da atual situação dos crimes ambientais cometido em sua área de atuação. Portanto, será demonstrado a seguir como será realizada esta tarefa de gestão de fiscalização dos danos ambientais.

Apresentam-se as opções de consultas do sistema, sendo que a partir delas será feito o gerenciamento da incidência de crimes ambientais em determinada região de nossa área de atuação.

Será possível realizar consultas gerais por período. Para tanto, deve-se informar o período desejado e receber o resultado geral das denúncias. Há também a possibilidade de realizar consultas por município e por natureza, bem como consulta personalizada.

Para demonstrar a funcionalidade do sistema, foi criada uma tabela com 60 registros fictícios de crimes ambientais comuns na área do $2^{\circ}$ Pelotão da Polícia Militar de Maracajá, e foram feitas algumas simulações, conforme Figura 10.5, demonstrando a gestão do cadastro de ocorrências ambientais da região, em que é possível identificar o atendimento de apenas $60 \%$ das ocorrências do período.

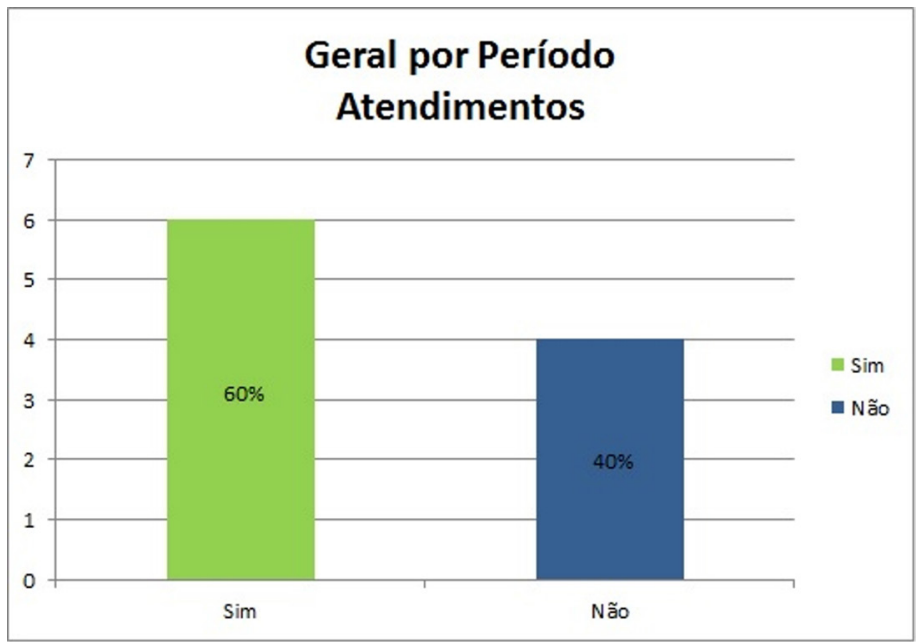

Figura 10.5 Gráfico de ocorrências por período. 
Realizando uma consulta ampla, sem filtros, o sistema poderia gerar um gráfico com os 60 registros que temos em nossa base de dados e, assim, demonstrar onde estão os maiores problemas de crimes ambientais, possibilitando elaborar ações para minimizar os danos contra o meio ambiente.

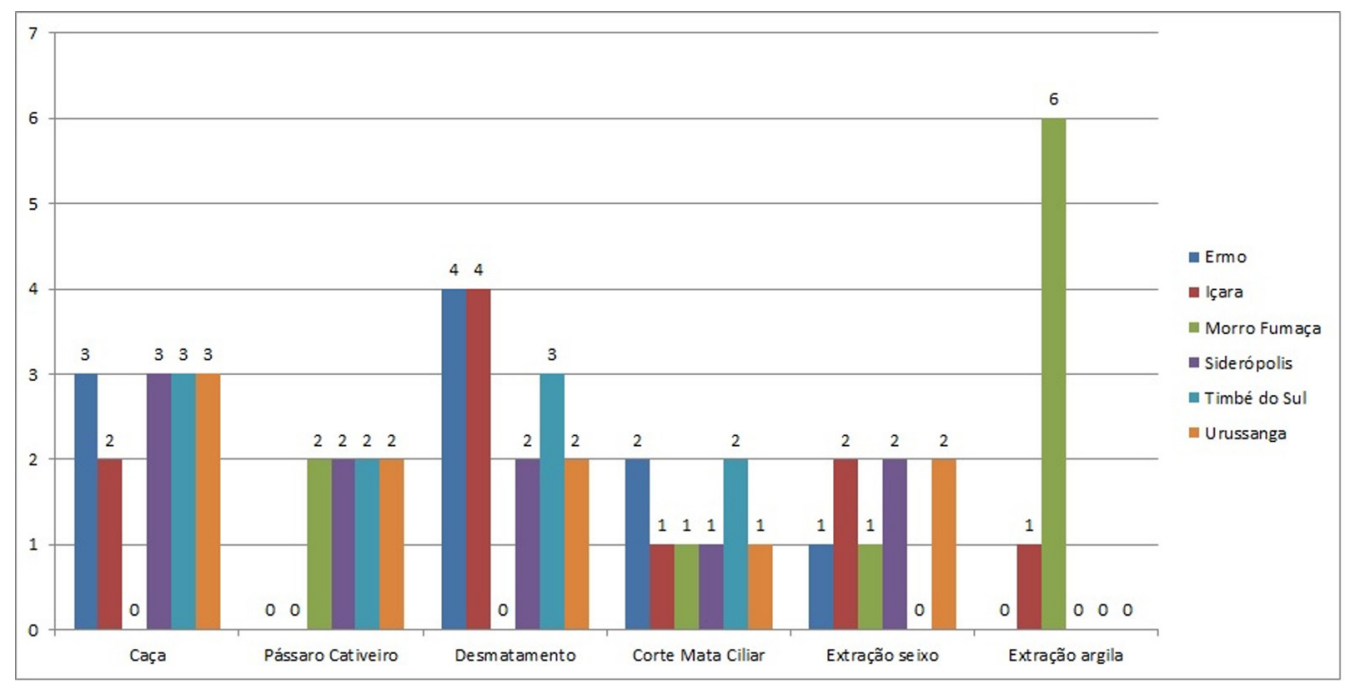

Figura 10.6 Gráfico das ocorrências por natureza e por município.

\section{CONCLUSÕES}

O objetivo principal deste trabalho foi de propor um sistema computacional que possa ser aplicado pela Polícia Militar Ambiental (PMA) no Estado de Santa Catarina para a gestão da fiscalização ambiental. Para que este objetivo fosse alcançado, foi necessário acompanhar e descrever as principais atividades da PMA no que tange o processo de registro e acompanhamento de processos advindos de denúncias realizadas de diferentes formas, como via web, telefone etc.

Após o levantamento dos requisitos do sistema, foi realizada uma pesquisa junto aos órgãos de fiscalização dos diversos estados da federação, com o intuito de identificar sistemas que atendessem à demanda local e que, porventura, pudessem ser adotados na sua totalidade ou com pequenas adaptações. Neste aspecto, não foi possível localizar um sistema que atendesse às necessidades da Polícia Ambiental de Maracajá e, por este motivo, fez-se necessário propor um protótipo a partir das informações obtidas na etapa de elicitação de requisitos.

É possível verificar que a demanda da Polícia Militar Ambiental é bastante específica para suas atividades diárias e que as políticas públicas não têm acompanhado essas necessidades. Com este trabalho de levantamento de requisitos e 
modelagem do sistema, propõe-se como trabalho futuro a implementação de um protótipo funcional para a validação do modelo sugerido.

\section{REFERÊNCIAS}

CURI, D. Gestão ambiental. São Paulo: Pearson, 2012.

OMETO, A. R.; FILHO, A. G.; PERES, R. B. Gestão ambiental de empresas. Rio de Janeiro: Elsevier, 2013.

PHILIPPI, J. A.; ROMÉRO, M. A.; BRUNA, G. C. Curso de Gestão Ambiental. 1. ed. Barueri: Manole, 2004.

SOMMERVILLE, I. Engenharia de software. 8. ed. v. XIV. São Paulo: Pearson AddisonWesley, 2007. 